\title{
Recurrent Carcinoma of Unknown Primary
}

National Cancer Institute

\section{Source}

National Cancer Institute. Recurrent Carcinoma of Unknown Primary. NCI Thesaurus.

Code $C 9181$.

The reemergence of carcinoma from an unknown primary after a period of remission. 